DIW BERLIN

Discussion

Papers
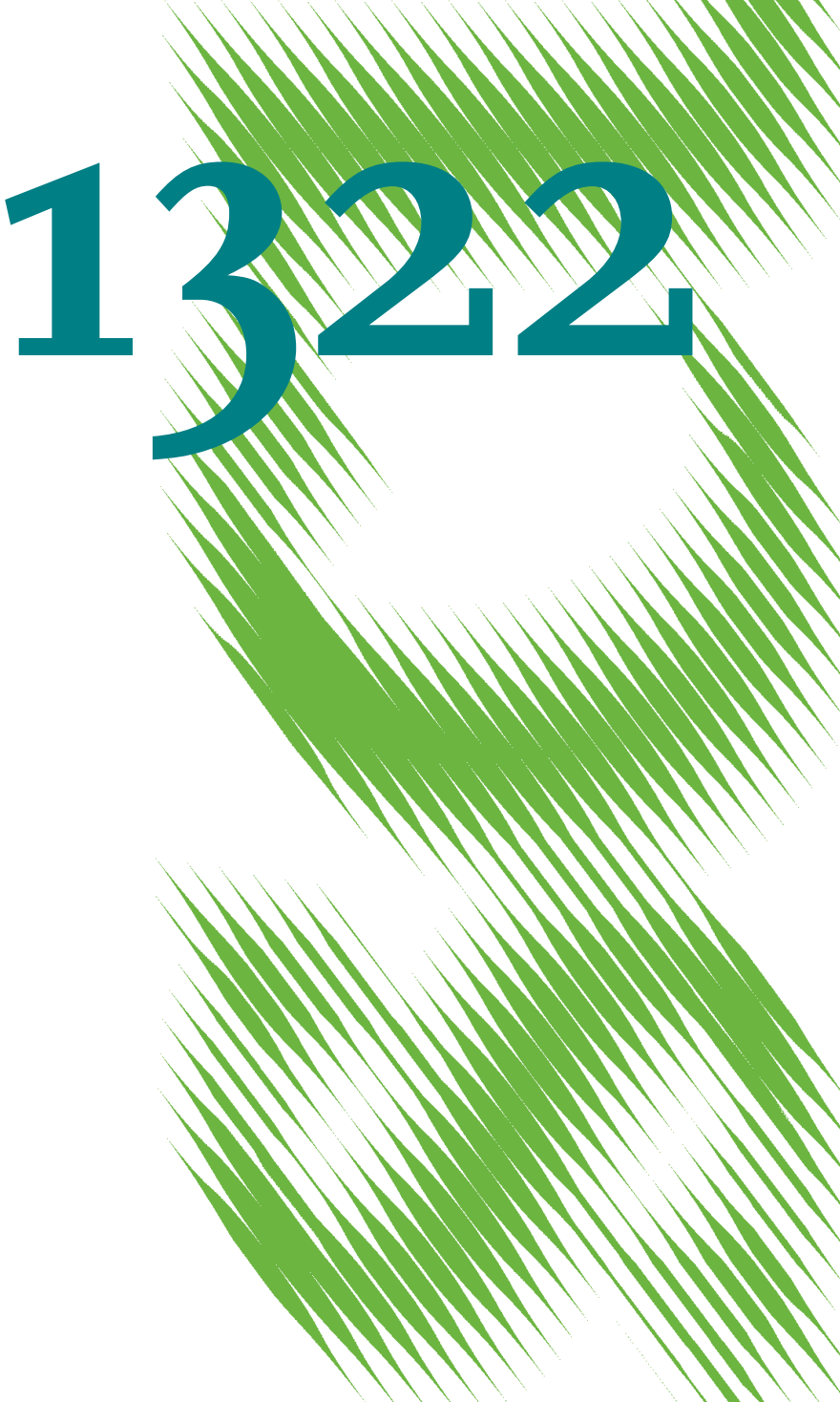

Clustering Properties of Merger Waves: Space, Time or Industry? 
Opinions expressed in this paper are those of the author(s) and do not necessarily reflect views of the institute.

IMPRESSUM

(C) DIW Berlin, 2013

DIW Berlin

German Institute for Economic Research

Mohrenstr. 58

10117 Berlin

Tel. $+49(30) 89789-0$

Fax +49 (30) $89789-200$

http://www.diw.de

ISSN print edition $1433-0210$

ISSN electronic edition 1619-4535

Papers can be downloaded free of charge from the DIW Berlin website:

http://www.diw.de/discussionpapers

Discussion Papers of DIW Berlin are indexed in RePEc and SSRN:

http://ideas.repec.org/s/diw/diwwpp.html

http://www.ssrn.com/link/DIW-Berlin-German-Inst-Econ-Res.html 


\title{
Clustering properties of merger waves: space, time or industry?
}

\author{
Florian Szücs* \\ DIW Berlin, Mohrenstr. 58, 10117 Berlin, Germany
}

July 2013

\begin{abstract}
We study the degree of agglomeration of acquisition activity within clusters of temporal, geographic and industrial proximity based on almost 600,000 individual transactions. The findings indicate that significant clustering occurs in time and across industries, while the results on geographic clustering are mixed. This supports the view that merger waves are mostly driven by neoclassical motives.

Keywords: merger wave; clustering; acquisitions; neoclassical; behavioral

JEL codes: L2, G3
\end{abstract}

\section{Introduction}

It is well known that the occurrence of mergers and acquisitions (M\&A) is not uniformly distributed, but that M\&A tend to accumulate across various dimensions - a phenomenon often referred to as merger waves. This letter employs a sample of almost 600,000 acquisitions that occurred between 1988 and 2009 to study the clustering properties of merger waves. The existing literature has proposed three dimensions in which M\&A agglomerate:

First, and most obviously, M\&A cluster in time; evaluating aggregate M\&A activity over successive periods yields the characteristic and eponymous wave pattern. The literature has shown that merger waves can be reasonably well depicted by Markov-switching processes (Gärtner and Halbheer, 2009; Town, 1992), sine waves (Golbe and White, 1993) or long-memory processes (Barkoulas et al., 2001). In the analysis we will therefore consider the effect of M\&A in temporally adjacent clusters on current M\&A.

Second, neoclassical theories see mergers as a means of asset reallocation between efficient and inefficient firms in response to industry shocks and suggest that merger waves occur in industries experiencing fundamental changes (Andrade and Stafford, 2004; Harford, 2005; Jovanovic and Rousseau, 2002; Mitchell and Mulherin, 1996). This yields the prediction that merger waves not only cluster in time, but also in industries where an exogenous shock necessitates asset reallocation as well as in related industries. ${ }^{1}$

Third, behavioral explanations emphasize the role of market imperfections: companies whose stock is overvalued by the market would like to exchange it for real assets (Shleifer and Vishny, 2003) and irrational managers might be prone to engage in too many mergers (Mueller, 1969). These explanations provide a link between the often concurrent phenomena of stock market booms and merger waves and suggest that acquisitions cluster around countries with high stock market performance (Clarke and Ioannidis, 1996; Erel et al., 2012). ${ }^{2}$

\footnotetext{
*Tel.: +49 30 89789-552, e-mail: fszuecs@diw.de. I would like to thank Tomaso Duso and Klaus Gugler for helpful discussions.

${ }^{1}$ While it might be argued that some shocks - i.e. deregulation of an industry in a specific country - would entail clustering at the country level as well as clustering at the industry level, most shocks - i.e. product innovations or changes in production technology - are more likely to affect the whole branch. Furthermore, even country-specific industry shocks are likely to have an impact on similar industries in other countries.

${ }^{2}$ Symmetrically to above, one could make a case that behavioral shocks could cause clustering at the industry level as well. However, the geographic dimension seems more relevant here: stock market booms typically affect countries or regions rather than specific industries and other measures of market optimism, like GDP growth, are defined nationally. Cultural factors, like language and religion, play a role as well (Erel et al., 2012).
} 
Even though most economists would agree that the neoclassical and behavioral theories of merger waves are complementary rather than mutually exclusive, it is interesting to investigate which theory is the more relevant driving force behind merger clustering. ${ }^{3}$ This article presents a simple framework to quantify acquisitions in time-, industry- and geographic-space and analyzes which of these dimensions of clustering bears the most explanatory power for aggregate merger activity.

\section{Data and results}

\subsection{Sample and measurement}

The data on acquisitions is obtained from the Thomson Reuters 'Worldwide Mergers \& Acquisitions' database, containing all corporate acquisitions with a minimum deal value of 1 million USD and a minimum change of ownership of $5 \%$. We collect the date and values of transactions, as well as the industry classification and country of origin of the acquiring firms in 589,946 acquisitions that took place in the 22 year period between 1988 and 2009.

We then define clusters, the size of which is given by the total number of transactions, $\operatorname{acq}_{t, i, c}$, in a specific month $t$ (the time dimension), 4-digit sector $i$ (industry dimension) and country $c$ (geographic dimension). This variable is the dependent variable in all regressions. Next, we define measures of temporal clustering, $\tau_{t, i, c}$, industrial clustering, $\iota_{t, i, c}$ and country-level clustering, $\zeta_{t, i, c}$, where $\tau_{t, i, c}$ is defined as the sum of all acquisitions (in all industries and countries) in the previous and following period, $\iota_{t, i, c}$ is the sum of acquisitions in all countries and all industries but $i$, weighted by the degree of relatedness with industry $i$ and $\zeta_{t, i, c}$ is the sum of acquisitions in all industries and all countries but $c$, weighted by their geographical distance to $c$. Formally, we have

$$
\begin{aligned}
\tau_{t, i, c} & =\sum_{t \in\{t-1, t+1\}} \sum_{i, c} \mathrm{acq}_{t, i, c}, \\
\iota_{t, i, c} & =\sum_{-i, c} \mathrm{acq}_{t, i, c} \gamma_{i}, \\
\zeta_{t, i, c} & =\sum_{i,-c} \mathrm{acq}_{t, i, c} \delta_{c},
\end{aligned}
$$

where $-i(-c)$ indicates summation over all industries (countries) but the current one and $\gamma_{i}$ and $\delta_{c}$ are the weights. We exclude the current time period, industry or country in the construction of the clustering measures to mitigate endogeneity concerns and define the weights as follows: $\gamma_{i}$ is 1 for acquisitions within the same 3 -digit code, $2 / 3$ for acquisitions within the same 2 -digit code, $1 / 3$ if the first industry digit is the same and 0 if the industries are unrelated. ${ }^{4} \delta_{c}$ is the normalized inverse of the great-circle distance between two countries. The resulting measures of distance are then normalized to $[0,1]$ to make their regression coefficients more comparable.

In the estimations we include dummy variables for every month (255 variables), industry (914 variables) and country (108 variables $)^{5}$ in the sample to control for time, industry and country fixed-effects. We are thus interested in a model of the form

$$
\mathrm{acq}_{t, i, c}=\alpha_{0}+\alpha_{1} \tau_{t, i, c}+\alpha_{2} \iota_{t, i, c}+\alpha_{3} \zeta_{t, i, c}+\beta X+\varepsilon_{t, i, c},
$$

where $X$ contains the different fixed-effects variables and the $\alpha_{i}(i=1,2,3)$ measure the relevance of clustering in the respective dimensions.

Equation (4) is estimated by OLS and - to account for the fact that the dependent variable is leftcensored - using a tobit model. Since almost $80 \%$ of the sample consists of clusters, in which no acquisitions

\footnotetext{
${ }^{3}$ Gugler et al. (2012) exploit differences in the acquisition conduct of listed and unlisted firms to distinguish between different merger motives, finding that behavioral theories are consistent with the patterns they observe.

${ }^{4}$ Results are not strongly affected by the choice of industry weights.

${ }^{5}$ The data, as represented in figure 1, contain information on 158 countries. For the regressions, we require additional industry and macro information, which are unavailable for 50 small countries. Acquisitions from these countries account for roughly $6 \%$ of total $\mathrm{M} \& \mathrm{~A}$ in the sample period.
} 
occurred and the probability of a cluster having zero or nonzero acquisitions cannot plausibly be assumed to random, we also estimate a Heckman model to control for sample selection. ${ }^{6}$ The dependent variable in the first-stage regressions is a dummy indicating whether zero or a positive amount of acquisitions occurred in the current cluster and we select the instruments indicative of the competing merger wave hypotheses: industry shocks (changes in profitability, productivity, sales, employees, income and market capitalization in the 4-digit industry ${ }^{7}$ ) and stock market / macro performance (GDP; FDI, imports, exports, stock market capitalization (all relative to GDP) and the number of stock market listed companies ${ }^{8}$ ). The three measures of distance are included as well. In the second stage, equation (4) is re-estimated including the inverse Mills ratio and correcting standard errors for the inclusion of a constructed variable.

Note that since $\iota_{t, i, c}$ and $\zeta_{t, i, c}$ are measured on a monthly basis, they have an implicit time dimension. This seems reasonable since i) the 'baseline' merger activity of an industry or country is already captured by the inclusion of fixed-effects and ii) even industry or country-specific clustering has a limited temporal extent, e.g. shocks and booms. The explicit time measure, $\tau_{t, i, c}$, thus measures whether there is additional temporal clustering if the time dimension of industrial and geographic clustering is controlled for. To ensure that this does not confound effects, we estimate (4) in separate specifications, gradually introducing all three measures.

\subsection{Preliminary findings}

Figure 1 illustrates the clustering dimensions defined above. The top panel color-codes the quartiles of transaction volumes by country, normalized by 2008 GDP. The highest transaction volumes are observed in Canada and the US, all of Western Europe, Japan, South Korea, Australia, New Zealand and South Africa. The third quartile comprises large parts of Asia and South America, as well as some east-African nations. The second quartile consists of mostly African and eastern European countries and the lowest transaction volumes are observed in West African nations and the countries of the Greater Middle East. Measures of spatial autocorrelation, such as Geary's C or Moran's I indicate positive and significant autocorrelation. The lower-left panel of figure 1 shows the distribution of transaction values across 2-digit industries. The most notable peak occurs around industry 67 (investment offices and investors), two similarly-sized spikes are observed for industries 48 (communications) and 60 (banks). Further high activity sectors are 13 (oil and gas extraction), 28 (chemicals and allied products), 49 (electric, gas and sanitary services), 63 (insurance carriers) and 73 (business services). Finally, graphing transaction volumes per month in the lower-right panel we see the familiar shape of the two most recent merger waves: the 1990s merger wave, building up to its peak in 1999/2000 and then ending abruptly with the bursting of the dot-com bubble and the most recent wave, starting to gain momentum in 2003 and ending in late 2008 in the wake of the financial crisis.

\section{Figure 1 here}

\subsection{Regression analysis}

Columns (1) - (5) of table 1 contain the OLS results, which indicate positive and significant clustering in the time and industry dimensions, but not among countries. Thus while the spatial dimension is accounted for by the country fixed-effects, there is an additional concentration of acquisitions in neighboring industries or consecutive months of high activity. The country and industry coefficients are identical across specifications, the time coefficient decreases when the other two measures are included due to their implicit time dimension.

The tobit estimations in columns (6) - (10) yield qualitatively similar results for the time and industry measures, with larger coefficients. ${ }^{9}$ The coefficient of country clustering, on the other hand, becomes positively significant in this specification.

\section{Table 1 here}

\footnotetext{
${ }^{6}$ Di Giovanni (2005) and Wong (2008) pursue the same strategy to account for the nonrandomness of missing M\&A observations.

${ }^{7}$ Data are obtained from the Thomson Reuters Worldscope database.

${ }^{8}$ Data were downloaded from the World Bank's Open Data project.

${ }^{9}$ This can be attributed to the bias incurred by using OLS without accounting for censoring: coefficient estimates will be downwards-biased, the constant will be upwards-biased.
} 
Table 2 reports the results when using a two-step Heckman procedure to estimate acquisition clustering. The first-stage results show that acquisitions are more likely to occur in clusters with positive changes in productivity, sales and employment and clusters with negative changes in profitability, income and market capitalization. The probability of acquisitions also increases with GDP, FDI and imports as well as the number and market capitalization of listed firms, while it decreases with exports. The coefficients of the distance measures show that acquisition activity is (i) dispersed across industry/country clusters $\left(\tau_{t, i, c}<0\right)$, (ii) dispersed across countries $\left(\zeta_{t, i, c}<0\right)$, but (iii) more likely, if acquisition activity in related industries is high $\left(\iota_{t, i, c}>0\right)$.

Turning to the main regressions, we see that the inverse Mills ratio $(\lambda)$ assumes a significant coefficient in all regressions and that the correlation of error terms (the $\rho \mathrm{s}$ ) is considerable. This indicates that the use of a two-step estimation procedure is appropriate. The coefficients of the agglomeration measures confirm the existence of positive clustering in time and across industries and are slightly larger than those found in the OLS specification but smaller than the tobit coefficients. Geographical clustering now assumes a significantly negative coefficient, indicating that, after accounting for country fixed-effects, acquisition peaks occur in a geographically dispersed fashion. However, the effect of $\zeta_{t, i, c}$ is smaller in both size and significance than those of time and industry clustering. Thus while controlling for selection issues does not strongly affect the findings on temporal and industrial clustering, the results on spatial clustering are reversed by this.

\section{Table 2 here}

\section{Conclusion}

We provide an overview of the distribution of acquisitions between 1988 and 2009 in space, time and industry and study the degree of clustering in these dimensions. We find the claim that acquisitions tend to cluster across both time and industries supported by graphical evidence as well as OLS, tobit and Heckman analysis. Clustering by countries changes sign across specifications. In the preferred specification, which accounts for selection bias, we find a significantly negative coefficient, indicating geographic dispersion.

Thus while the findings on country clustering are mixed, we find that (i) acquisitions cluster in related industries in all regressions and (ii) the effect is larger and more significant than that of geographic proximity (and that of time as well). Under the assumption that industry clustering is indicative of neoclassical acquisition motives, while clustering around countries or stock markets is more consistent with behavioral explanations, the findings point to a predominance of neoclassical motives in the formation of merger waves.

\section{References}

Andrade, Gregor and Erik Stafford, "Investigating the economic role of mergers," Journal of Corporate Finance, 2004, 10 (1), 1-36.

Barkoulas, John T, Christopher F Baum, and Atreya Chakraborty, "Waves and persistence in merger and acquisition activity," Economics Letters, 2001, 70 (2), 237-243.

Clarke, Roger and Christos Ioannidis, "On the relationship between aggregate merger activity and the stock market: some further empirical evidence," Economics letters, 1996, 53 (3), 349-356.

Erel, Isil, Rose C Liao, and Michael S Weisbach, "Determinants of Cross-Border Mergers and Acquisitions," The Journal of Finance, 2012, 67 (3), 1045-1082.

Gärtner, Dennis L and Daniel Halbheer, "Are there waves in merger activity after all?," International Journal of Industrial Organization, 2009, 27 (6), 708-718.

Giovanni, Julian Di, "What drives capital flows? The case of cross-border M\&A activity and financial deepening," Journal of International Economics, 2005, 65 (1), 127-149.

Golbe, Devra L and Lawrence J White, "Catch a wave: The time series behavior of mergers," The Review of Economics and Statistics, 1993, pp. 493-499. 
Figure 1: Spatial, industrial and temporal clustering of acquisitions


Gugler, Klaus, Dennis C Mueller, and Michael Weichselbaumer, "The determinants of merger waves: An international perspective," International Journal of Industrial Organization, 2012, 30 (1), 115.

Harford, Jarrad, "What drives merger waves?," Journal of Financial Economics, 2005, 77 (3), 529-560.

Jovanovic, Boyan and Peter L Rousseau, "The Q-Theory of Mergers," The American Economic Review, 2002, 92 (2), 198-204.

Mitchell, Mark L and J Harold Mulherin, "The impact of industry shocks on takeover and restructuring activity," Journal of Financial Economics, 1996, 41 (2), 193-229.

Mueller, Dennis C, "A theory of conglomerate mergers," The Quarterly Journal of Economics, 1969, 83 (4), 643-659.

Shleifer, Andrei and Robert W Vishny, "Stock market driven acquisitions," Journal of Financial Economics, 2003, 70 (3), 295-311.

Town, R. J., "Merger Waves and the Structure of Merger and Acquisition Time-Series," Journal of Applied Econometrics, 1992, 7, pp. S83-S100.

Wong, Wei-Kang, "Comparing the fit of the gravity model for different cross-border flows," Economics Letters, 2008, 99 (3), 474-477. 


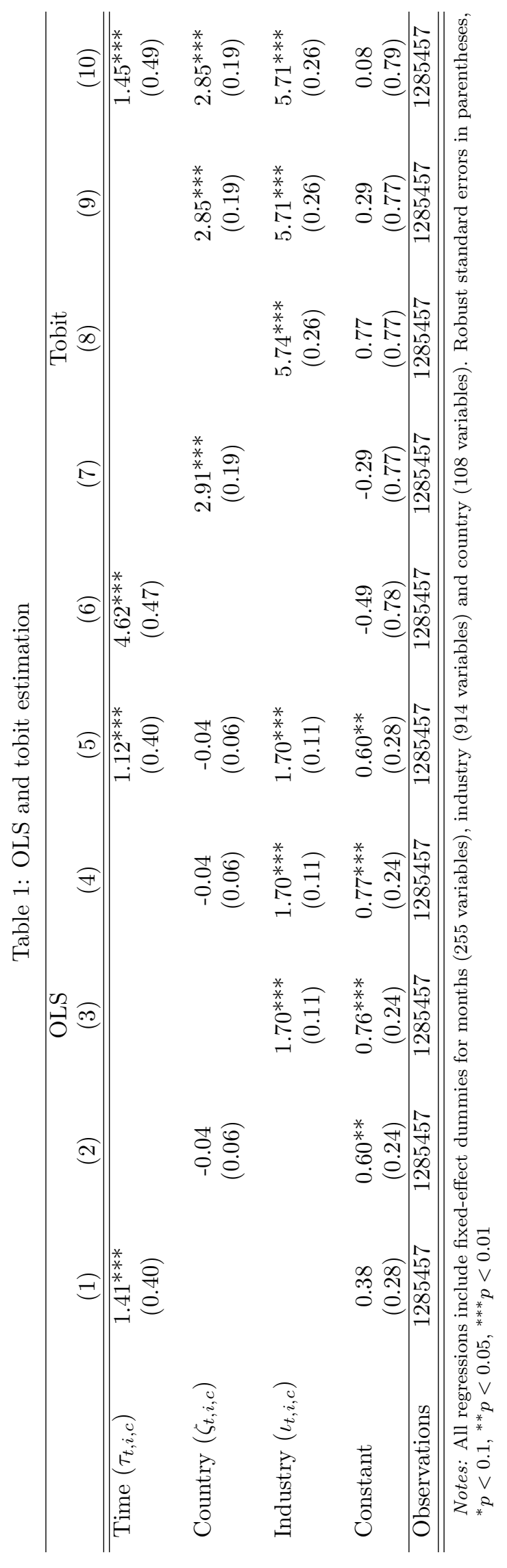


Table 2: Two-step Heckman estimation

\begin{tabular}{|c|c|c|c|c|c|}
\hline & $(1)$ & $(2)$ & $(3)$ & $(4)$ & $(5)$ \\
\hline \multicolumn{6}{|l|}{ 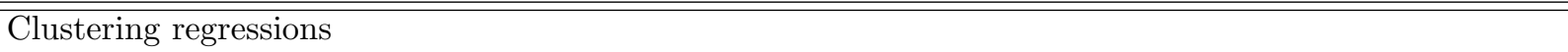 } \\
\hline Time $\left(\tau_{t, i, c}\right)$ & $\begin{array}{c}1.75^{* * *} \\
(0.50)\end{array}$ & & & & $\begin{array}{c}2.10^{* * *} \\
(0.54)\end{array}$ \\
\hline Country $\left(\zeta_{t, i, c}\right)$ & & $\begin{array}{c}-0.57^{* *} \\
(0.24)\end{array}$ & & $\begin{array}{c}-0.60^{* *} \\
(0.24)\end{array}$ & $\begin{array}{c}-0.78^{* * *} \\
(0.24)\end{array}$ \\
\hline Industry $\left(\iota_{t, i, c}\right)$ & & & $\begin{array}{c}2.02^{* * *} \\
(0.27)\end{array}$ & $\begin{array}{c}2.07^{* * *} \\
(0.28)\end{array}$ & $\begin{array}{c}1.99^{* * *} \\
(0.28)\end{array}$ \\
\hline$\lambda$ & $\begin{array}{c}-1.54^{* * *} \\
(0.11)\end{array}$ & $\begin{array}{c}-1.52^{* * *} \\
(0.12)\end{array}$ & $\begin{array}{c}-1.20^{* * *} \\
(0.13)\end{array}$ & $\begin{array}{c}-0.89^{* * *} \\
(0.12)\end{array}$ & $\begin{array}{c}-0.89^{* * *} \\
(0.12)\end{array}$ \\
\hline Constant & $\begin{array}{c}0.80 \\
(1.17)\end{array}$ & $\begin{array}{c}1.15 \\
(1.15)\end{array}$ & $\begin{array}{c}0.90 \\
(1.16)\end{array}$ & $\begin{array}{c}0.30 \\
(1.16)\end{array}$ & $\begin{array}{l}-0.02 \\
(1.17)\end{array}$ \\
\hline First-stage regressions & & & & & \\
\hline$\Delta$ Productivity & $\begin{array}{c}0.00^{* * *} \\
(0.00)\end{array}$ & $\begin{array}{c}0.00^{* * *} \\
(0.00)\end{array}$ & $\begin{array}{c}0.00^{* * *} \\
(0.00)\end{array}$ & $\begin{array}{c}0.00^{* * *} \\
(0.00)\end{array}$ & $\begin{array}{c}0.00^{* * * *} \\
(0.00)\end{array}$ \\
\hline$\Delta$ Sales & $\begin{array}{c}0.06^{* * *} \\
(0.00)\end{array}$ & $\begin{array}{c}0.06^{* * *} \\
(0.00)\end{array}$ & $\begin{array}{c}0.05^{* * *} \\
(0.00)\end{array}$ & $\begin{array}{c}0.06^{* * *} \\
(0.00)\end{array}$ & $\begin{array}{c}0.06^{* * *} \\
(0.00)\end{array}$ \\
\hline$\Delta$ Employment & $\begin{array}{c}0.07^{* * *} \\
(0.00)\end{array}$ & $\begin{array}{c}0.07^{* * *} \\
(0.00)\end{array}$ & $\begin{array}{c}0.04^{* * *} \\
(0.00)\end{array}$ & $\begin{array}{c}0.06^{* * *} \\
(0.00)\end{array}$ & $\begin{array}{c}0.06^{* * *} \\
(0.00)\end{array}$ \\
\hline$\Delta$ Market Cap. & $\begin{array}{c}-0.12^{* * *} \\
(0.00)\end{array}$ & $\begin{array}{c}-0.12^{* * *} \\
(0.00)\end{array}$ & $\begin{array}{c}-0.10^{* * *} \\
(0.00)\end{array}$ & $\begin{array}{c}-0.12^{* * *} \\
(0.00)\end{array}$ & $\begin{array}{c}-0.12^{* * *} \\
(0.00)\end{array}$ \\
\hline$\Delta$ Profitability & $\begin{array}{c}-0.16^{* * *} \\
(0.06)\end{array}$ & $\begin{array}{c}-0.18^{* * *} \\
(0.06)\end{array}$ & $\begin{array}{c}-0.19^{* * *} \\
(0.06)\end{array}$ & $\begin{array}{c}-0.16^{* * *} \\
(0.06)\end{array}$ & $\begin{array}{c}-0.13^{* *} \\
(0.06)\end{array}$ \\
\hline$\Delta$ Income & $\begin{array}{c}-0.00^{* * *} \\
(0.00)\end{array}$ & $\begin{array}{c}-0.00^{* * *} \\
(0.00)\end{array}$ & $\begin{array}{c}-0.00^{* * *} \\
(0.00)\end{array}$ & $\begin{array}{c}-0.00^{* * *} \\
(0.00)\end{array}$ & $\begin{array}{c}-0.00^{* * *} \\
(0.00)\end{array}$ \\
\hline $\ln ($ GDP in $\$)$ & $\begin{array}{c}0.19^{* * *} \\
(0.00)\end{array}$ & $\begin{array}{c}0.20^{* * *} \\
(0.00)\end{array}$ & $\begin{array}{c}0.18^{* * *} \\
(0.00)\end{array}$ & $\begin{array}{c}0.20^{* * *} \\
(0.00)\end{array}$ & $\begin{array}{c}0.20^{* * *} \\
(0.00)\end{array}$ \\
\hline FDI/GDP & $\begin{array}{c}1.15^{* * *} \\
(0.03)\end{array}$ & $\begin{array}{c}1.24^{* * *} \\
(0.03)\end{array}$ & $\begin{array}{c}0.87^{* * *} \\
(0.03)\end{array}$ & $\begin{array}{c}1.19^{* * *} \\
(0.03)\end{array}$ & $\begin{array}{c}1.16^{* * *} \\
(0.03)\end{array}$ \\
\hline Imports/GDP & $\begin{array}{c}1.38^{* * *} \\
(0.03)\end{array}$ & $\begin{array}{c}1.37^{* * *} \\
(0.03)\end{array}$ & $\begin{array}{c}1.35^{* * *} \\
(0.03)\end{array}$ & $\begin{array}{c}1.35^{* * *} \\
(0.03)\end{array}$ & $\begin{array}{c}1.36^{* * *} \\
(0.03)\end{array}$ \\
\hline Exports/GDP & $\begin{array}{c}-1.07^{* * *} \\
(0.03)\end{array}$ & $\begin{array}{c}-1.07^{* * *} \\
(0.03)\end{array}$ & $\begin{array}{c}-1.05^{* * *} \\
(0.03)\end{array}$ & $\begin{array}{c}-1.05^{* * *} \\
(0.03)\end{array}$ & $\begin{array}{c}-1.05^{* * *} \\
(0.03)\end{array}$ \\
\hline $\ln$ (Total listed firms) & $\begin{array}{c}0.10^{* * *} \\
(0.00)\end{array}$ & $\begin{array}{c}0.08^{* * *} \\
(0.00)\end{array}$ & $\begin{array}{c}0.11^{* * *} \\
(0.00)\end{array}$ & $\begin{array}{c}0.08^{* * *} \\
(0.00)\end{array}$ & $\begin{array}{c}0.09^{* * * *} \\
(0.00)\end{array}$ \\
\hline Market Cap./GDP & $\begin{array}{c}0.16^{* * *} \\
(0.00)\end{array}$ & $\begin{array}{c}0.15^{* * *} \\
(0.00)\end{array}$ & $\begin{array}{c}0.13^{* * *} \\
(0.00)\end{array}$ & $\begin{array}{c}0.15^{* * *} \\
(0.00)\end{array}$ & $\begin{array}{c}0.16^{* * * *} \\
(0.00)\end{array}$ \\
\hline Time $\left(\tau_{t, i, c}\right)$ & $\begin{array}{c}-0.33^{* * *} \\
(0.01)\end{array}$ & & & & $\begin{array}{c}-0.38^{* * *} \\
(0.01)\end{array}$ \\
\hline Country $\left(\zeta_{t, i, c}\right)$ & & $\begin{array}{c}-0.36^{* * *} \\
(0.01)\end{array}$ & & $\begin{array}{c}-0.49^{* * *} \\
(0.01)\end{array}$ & $\begin{array}{c}-0.20^{* * *} \\
(0.01)\end{array}$ \\
\hline Industry $\left(\iota_{t, i, c}\right)$ & & & $\begin{array}{c}0.71^{* * *} \\
(0.01) \\
\end{array}$ & $\begin{array}{c}0.92^{* * *} \\
(0.01) \\
\end{array}$ & $\begin{array}{c}1.03^{* * *} \\
(0.02)\end{array}$ \\
\hline$\rho$ & -0.327 & -0.323 & -0.260 & -0.195 & -0.194 \\
\hline Observations & 1285457 & 1285457 & 1285457 & 1285457 & 1285457 \\
\hline
\end{tabular}

Notes: All regressions include fixed-effect dummies for months (255 variables), industry (914 variables) and country (108 variables). Standard errors in parentheses, ${ }^{*} p<0.1,{ }^{* *} p<0.05,{ }^{* * *} p<0.01$ 